\title{
Digitalization - mainstream in optimizing the solution of breeding problems
}

\author{
G.V. Kalinkina*, A.V. Dubrovin, N.A. Kuptsova and A.A. Datsyshin
}

Federal State Budgetary Scientific Institution "All-Russian Research Institute of Horse Breeding", 391105, Institute of Horse Breeding, Divovo settlement, Rybnovsky District, Ryazan Region, Russia

\begin{abstract}
In the Strategy of Scientific and Technological Development of the Russian Federation, technical and technological modernization of all sectors of the national economy is defined as a strategic condition for the effective development of the Russian economy. Along with other branches of animal husbandry, horse breeding is also subject to modernization, especially in terms of optimizing the solution of breeding problems. The assessment of typicality and conformation becomes extremely important for those breeds where breeding work has been focused on maintaining an authentic type of constitution for a long time. The purpose of the research was to analyze alternative methods for assessing the conformation of horses of different breeds and productivity directions, to develop a method for photographing animals with subsequent image processing using digital technologies. The article discusses the actual problem of the subjectivity of horse conformation evaluation. It has been determined that obtaining sufficiently reliable data is possible both from a photograph taken with a camera with a long-focus lens and using a smartphone camera. Significant conformation differences have been established between the original and Russian populations of Shetland ponies. The expediency of using an innovative assessment method that meets the modern needs of horse breeding was shown.
\end{abstract}

\section{Introduction}

The digitalization of agriculture is becoming the main vector of its development. Among the urgent tasks is the development of a system for digital transformation of methods for managing the selection of agricultural animal breeds.

Valuation is an important selection method for assessing the breeding value of an animal. Horses are valuated according to a set of traits, including an assessment of the conformation and measurements based on the visual perception of the animal's forms and its measurement.

In horse breeding, the conformation assessment is given special importance, since it allows to judge the constitution and the animal's development degree, to assess the traits'

\footnotetext{
* Corresponding author: labgenetics79@gmail.com
} 
expressiveness of the breed and productivity, and also to establish which of its features are desirable and which are unfavorable for a particular type of use [1,2].

Traditionally, the assessment of horse conformation is carried out by a contact method and is based on measuring and descriptive methods, each of which is not devoid of subjectivity, which can often lead to erroneous conclusions about the quality and breeding value of the animal. In addition, this process is quite laborious and often time consuming $[3,4,5]$.

The current development pace of breeding requires high-tech methods for assessing the quality of animals. Digital technologies will allow breeding scientists to approach the solution of the assigned tasks using new methodological aspects due to the emergence and distribution of original technical means and software solutions.

The main purpose of this study was to analyze alternative methods for assessing the conformation of different horse breeds and areas of productivity, to demonstrate new directions in the field of digital technologies suitable for adaptation to solve this problem.

\section{Materials and methods}

The material for the study was:

- works of domestic and foreign authors devoted to the study of modern high-tech methods of expert horses evaluation;

- 18 stallions: 4 - Orlov Trotter, 1 - Tersk, 1 - Vyatka, 12 - Akhal-Teke;

- photographs of two populations' representatives of Shetland ponies: original $(n=8)$ and Russian $(\mathrm{n}=8)$.

The photographs were taken with a SONY ILCE-6000 camera with an equivalent focal length for $35 \mathrm{~mm}$ film (hereinafter referred to as FL), an Honor 10 smartphone with $27 \mathrm{~mm}$ FL and a Minolta film camera with a $100 \mathrm{~mm}$ lens (the negatives were further scanned with a CANON LIDE 600 photo scanner).

Markers' layout was used as a basis for determining the scale during shooting; it was applied with paint (preferably) or laid out with battens or cords on a flat horizontal platform with a hard surface. A line of symmetry was drawn dividing the left and right limbs of the horse. On the dividing line, a base of $200 \mathrm{~cm}$ was marked with a contrasting paint, perpendiculars were dropped on both sides of the midline $-100 \mathrm{~cm}(50 \mathrm{~cm}$ each to the left and right sides) (Figure 1).

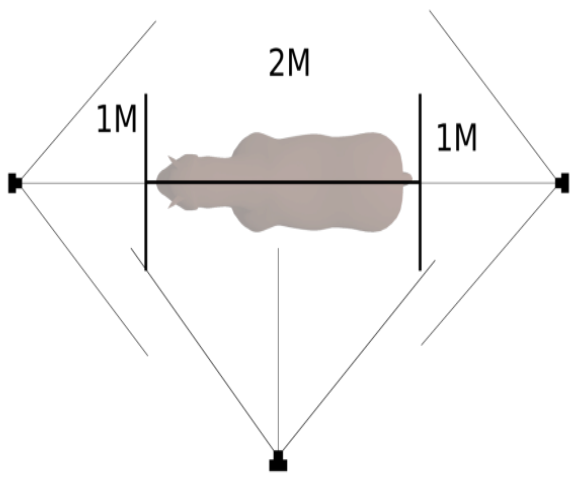

Fig. 1. The scheme of marking and setting the horse when photographing.

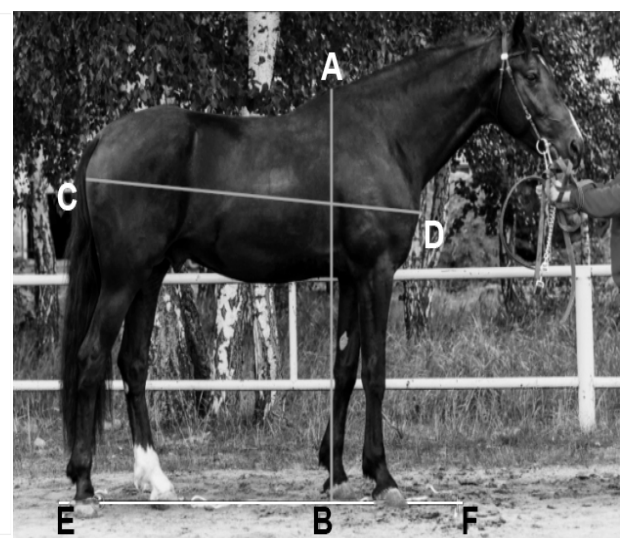

Fig. 2. Work window of the GIMP graphic editor. 
The photographing device was positioned over a point lying on the perpendicular line to the middle of the horse's baseline. The device allocation height corresponded to the level of the animal's humeroscapular joint.

Horse positioning was carried out in accordance with the rules of zootechnical photography - the animal leaned evenly on all four legs, stood in a natural free posture.

The background was contrasting to horse colour.

The photographs were taken in natural light. Light intensity was not considered.

The photos of the horses were processed in the graphics editor GIMP (free software). With the help of this program (the "Gauge" tool), the dimensions between the following points were obtained by the photos: EF - zero-mark, AB - withers height, $\mathrm{CD}$ - oblique body length (Figure 2). The unit of measurement - pixels.

Conversion of the size in pixels to metric sizes was carried out according to the formula:

$$
X_{c m}=\left(M_{c m} * X_{p x}\right) / M_{p x}
$$

where $\mathrm{X}_{\mathrm{cm}}$ is the required size $(\mathrm{cm}) ; \mathrm{M}_{\mathrm{cm}}$ - mark size (cm); $\mathrm{X}_{\mathrm{px}}$ - size (pixel); $\mathrm{M}_{\mathrm{px}}-$ mark size (pixel)

To control the accuracy of measurements obtained by computer processing of photographs, the following horse measurements were obtained by the classical method: withers height, oblique body length, chest girth, cannon girth.

To exclude distortions of photo measurements associated with a possible change in the position of the markers' layout during photography, the proportion coefficient of withers height to the oblique body length ratio was calculated. The calculation was made according to the formula:

$$
K=W H / S B L
$$

where $\mathrm{K}$ is the coefficient of proportion; WH - withers height; SBL - slant body length.

The research results were processed biometrically using the methods of variation statistics using the Microsoft Office Excel program.

From the horse images of the original and Russian populations of Shetland ponies in ImageJ (free software), vector lengths between reference points (pixels) and angles (degrees) were measured. The markers were plotted in the GIMP graphics editor. The measurements were used to calculate the ratios of individual measurements to each other. The calculation was made according to the formulas:

format index (IF) = oblique body length / withers height

upstanding index $(U I)=$ length of the front leg / withers height

outgrowth index $(\mathrm{OI})=$ croup height / withers height

$T L / B L$ index $=$ top length $/$ bottom length

$H L L / F L L$ index $=$ hind leg length $/$ fore leg length

$H L L / W H$ index $=$ hind leg length / withers height

FLL/CH index = fore leg length / croup height

$H L L / C H$ index $=$ hind leg length / croup height

Statistical data processing was carried out in the KNIME package - a free open source data mining system (KNIME GmbH, Konstanz, Germany).

\section{Results and Discussions}

Traditionally, a measuring stick and measuring tape are used for hippometric measurements. However, the combination of these tools does not allow to quickly make the 
maximum number of measurements in a minimum of time. Therefore, in our opinion, the photographic method should be the basis for a new high-tech solution for assessing the horse's conformation.

So, a new method of phenotypic assessment of the horse's conformation based on photography was proposed relatively recently, when a spatial model of its shape is extracted from a standardized image using geometric morphometry. To improve the assessment of conformational traits, Druml T. et al. proposed their own method for comparing subjective assessments of classifiers with objective horse measurements by means of geometric morphometry [6].

This topic is not new for domestic hippology. The beginning of this research direction was laid in the 80 s of the last century by scientists of the breeding department of the AllRussian Research Institute of Horse Breeding.

In their works, E.M. Pern et al. demonstrated the advantage of processing photographs in the computer program "HORSE" over taking measurements directly from a horse: ease of measurements, the ability to take a larger number of measurements, measure the angles of joints and calculate the area of functional triangles; as well as the inclusion of past generations in the study of horse confirmation characteristics using materials from the photo bank of the All-Russian Research Institute of Horse Breeding [7]. It was noted that any visible deviations from the standard zootechnical setting of the animal in the photograph give significant discrepancies in measurements the length of the head and neck, as well as the working angle of the neck. In addition, it was found that the result does not depend on the "hands" of different operators entering the initial data into the program [8].

In 1999, scientists from the All-Russian Research Institute of Horse Breeding created a more labile and easier-to-use program "YUS "Exterior 2000" for obtaining measurements from the image. Based on the entered withers height value, 27 absolute and 20 relative measurements were calculated. The possibility of linking images with the central database of pedigree registration was provided [4].

In 2020, the specialists of the All-Russian Research Institute of Horse Breeding continued the work on developing the methods for the non-contact assessment of horses' confirmation.

Table 1. Measurement results of horses of different breeds.

\begin{tabular}{|c|c|c|c|c|c|c|c|c|c|c|c|c|c|}
\hline \multirow{4}{*}{$\begin{array}{c}\text { Bre } \\
\text { ed }\end{array}$} & \multirow{4}{*}{$\begin{array}{l}\text { No. } \\
\text { pho } \\
\text { to }\end{array}$} & \multicolumn{6}{|c|}{ Horse measurements } & \multicolumn{2}{|c|}{ Mark dimensions } & \multicolumn{2}{|c|}{ Scale factor } & \multicolumn{2}{|c|}{ FL } \\
\hline & & \multirow{2}{*}{\multicolumn{2}{|c|}{ actual $(\mathrm{cm})$}} & \multicolumn{4}{|c|}{ photo measurements } & & & \multirow{3}{*}{$\begin{array}{c}\text { actual } \\
\text { measur } \\
\text { ements }\end{array}$} & \multirow{3}{*}{$\begin{array}{l}\text { photo } \\
\text { measur } \\
\text { ements }\end{array}$} & \multirow{3}{*}{$\begin{array}{c}\text { Error } \\
(\%)\end{array}$} & \multirow[t]{3}{*}{$\mathrm{mm}$} \\
\hline & & & & \multicolumn{2}{|c|}{$\mathrm{cm}$} & \multicolumn{2}{|c|}{ pixel } & & & & & & \\
\hline & & WH & SBL & WH & SBL & WH & SBL & pixel & $\mathrm{cm}$ & & & & \\
\hline \multirow{4}{*}{$\begin{array}{l}\text { Orl } \\
\text { ov } \\
\text { Tro } \\
\text { tter }\end{array}$} & 01 & 161.0 & 163.0 & 160.1 & 166.13 & 3239.0 & 3359.0 & 4045.7 & 200.0 & 0.988 & 0.964 & 2.375 & 90 \\
\hline & 02 & 160.0 & 163.0 & 160.3 & 165.1 & 3224.0 & 3320.0 & 4022.0 & 200.0 & 0.982 & 0.971 & 1.071 & 90 \\
\hline & 03 & 159.0 & 159.0 & 162.8 & 163.8 & 3261.0 & 3280.0 & 4005.0 & 200.0 & 1.000 & 0.994 & 0.579 & 90 \\
\hline & 04 & 167.0 & 167.0 & 180.0 & 181.0 & 3330.0 & 3349.0 & 3700.0 & 200.0 & 1.000 & 0.994 & 0.567 & 90 \\
\hline $\begin{array}{l}\mathrm{Vy} \\
\text { atk } \\
\text { a }\end{array}$ & 01 & 146.0 & 156.0 & 130.4 & 149.7 & 4576.0 & 5250.0 & 3508.0 & 100.0 & 0.936 & 0.872 & 6.868 & 27 \\
\hline $\begin{array}{l}\text { Ter } \\
\text { sk }\end{array}$ & 01 & 156.0 & 155.0 & 138.6 & 145.9 & 2966.0 & 3123.3 & 2140.1 & 100.0 & 1.006 & 0.950 & 5.645 & 27 \\
\hline \multirow{8}{*}{$\begin{array}{l}\text { Ak } \\
\text { hal } \\
- \\
\text { Te } \\
\text { ke }\end{array}$} & 01 & 161.0 & 168.0 & 160.2 & 169.2 & 3771.0 & 3982.2 & 2354.0 & 100.0 & 0.958 & 0.947 & 1.186 & 100 \\
\hline & 02 & 162.0 & 170.0 & 161.8 & 171.6 & 712.0 & 755.0 & 440.0 & 100.0 & 0.953 & 0.943 & 1.038 & 100 \\
\hline & 03 & 160.0 & 165.0 & 160.4 & 167.1 & 1484.0 & 1546.0 & 925.0 & 100.0 & 0.970 & 0.960 & 1.011 & 100 \\
\hline & 04 & 156.0 & 157.0 & 153.7 & 166.9 & 455.0 & 494.0 & 296.0 & 100.0 & 0.994 & 0.921 & 7.304 & 30 \\
\hline & 05 & 155.0 & 161.0 & 154.7 & 169.8 & 498.0 & 546.6 & 322.0 & 100.0 & 0.963 & 0.911 & 5.365 & 30 \\
\hline & 06 & 155.0 & 156.0 & 153.2 & 166.7 & 524.0 & 570.2 & 342.0 & 100.0 & 0.994 & 0.919 & 7.510 & 30 \\
\hline & 07 & 156.0 & 153.0 & 152.9 & 152.6 & 506.0 & 505.0 & 331.0 & 100.0 & 1.020 & 1.002 & 1.729 & 30 \\
\hline & 08 & 158.0 & 153.0 & 150.6 & 153.5 & 512.0 & 522.0 & 340.0 & 100.0 & 1.033 & 0.981 & 5.020 & 30 \\
\hline
\end{tabular}




\begin{tabular}{|c|c|c|c|c|c|c|c|c|c|c|c|c|}
\hline 09 & 160.0 & 156.0 & 157.1 & 158.9 & 539.0 & 545.0 & 343.0 & 100.0 & 1.026 & 0.989 & 3.573 & 30 \\
\hline 10 & 160.0 & 159.0 & 154.8 & 158.9 & 531.0 & 545.0 & 343.0 & 100.0 & 1.006 & 0.974 & 3.178 & 30 \\
\hline 11 & 158.0 & 160.0 & 153.9 & 160.3 & 514.0 & 535.5 & 334.0 & 100.0 & 0.988 & 0.960 & 2.800 & 30 \\
\hline 12 & 159.0 & 157.0 & 151.6 & 159.5 & 511.0 & 537.4 & 337.0 & 100.0 & 1.013 & 0.951 & 6.109 & 30 \\
\hline
\end{tabular}

In order to search for new methodologies in assessing horse conformation allowing to automate the process, to eliminate or to minimize the human factor influence on the assessment result to a large extent, a technique for photographing horses was worked out to collect and prepare a data array for an automated information system for assessing the morphometric horse characteristics. The possibility of obtaining accurate measurements of an animal from its photograph taken according to a given method with an arbitrary device for photographing (smartphone, camera, etc.) has been studied.

Table 1 shows the measurements of horses obtained by the classical method using a measuring stick and a measuring tape, as well as their photo measurements. The table shows that even having some discrepancies, all measurements were within acceptable limits and half of the indicators matched almost completely. In the case of the 04 horse image of the Orlov Trotter breed, the largest discrepancy in the measurement results was noted (table 2 ). This probably happened as a result of the markers' layout displacement by the animals, since the relative measurement error is $7.784 \%$ (for withers height) and $8.399 \%$ (for the oblique body length), and the ratio coefficient error is $0.567 \%$, this indicates the size correctness in the photograph, but the wrong marker size.

As expected, at a smaller focal length $(27 \mathrm{~mm})$, the measurement results are strongly influenced by optical distortion. When the focal length is more than $90 \mathrm{~mm}$, the average value of the relative error is within 1\%, which can be considered acceptable (Figure 3).

Table 2. Absolute and relative measurement errors.

\begin{tabular}{|c|c|c|c|c|c|c|c|c|}
\hline \multirow[t]{2}{*}{ Breed } & \multirow{2}{*}{$\begin{array}{l}\text { No. } \\
\text { photo }\end{array}$} & \multicolumn{2}{|c|}{ Withers height } & \multicolumn{2}{|c|}{ Oblique body length } & \multicolumn{2}{|c|}{ Scale factor } & \multirow[t]{2}{*}{$\delta \mathrm{K}(\%)$} \\
\hline & & $\Delta(\mathrm{cm})$ & $\delta(\%)$ & $\Delta(\mathrm{cm})$ & $\delta(\%)$ & $\begin{array}{c}\text { actual } \\
\text { measurements }\end{array}$ & $\begin{array}{c}\text { photo } \\
\text { measurements }\end{array}$ & \\
\hline \multirow{4}{*}{$\begin{array}{l}\text { Orlov } \\
\text { Trotter }\end{array}$} & 01 & -0.879 & -0.546 & 3.053 & 1.873 & 0.988 & 0.964 & -2.375 \\
\hline & 02 & 0.318 & 0.199 & 2.092 & 1.283 & 0.982 & 0.971 & -1.071 \\
\hline & 03 & 3.846 & 2.419 & 4.795 & 3.016 & 1.000 & 0.994 & -0.579 \\
\hline & 04 & 13.000 & 7.784 & 14.027 & 8.399 & 1.000 & 0.994 & -0.567 \\
\hline Vyatka & 01 & -15.555 & -10.654 & -6.342 & -4.065 & 0.936 & 0.872 & -6.868 \\
\hline Tersk & 01 & -17.408 & -11.159 & -9.058 & -5.844 & 1.006 & 0.950 & -5.645 \\
\hline \multirow{12}{*}{$\begin{array}{c}\text { Akhal- } \\
\text { Teke }\end{array}$} & 01 & -0.805 & -0.500 & 1.167 & 0.695 & 0.958 & 0.947 & -1.186 \\
\hline & 02 & -0.182 & -0.112 & 1.591 & 0.936 & 0.953 & 0.943 & -1.038 \\
\hline & 03 & 0.432 & 0.270 & 2.135 & 1.294 & 0.970 & 0.960 & -1.011 \\
\hline & 04 & -2.284 & -1.464 & 9.892 & 6.301 & 0.994 & 0.921 & -7.304 \\
\hline & 05 & -0.342 & -0.220 & 8.752 & 5.436 & 0.963 & 0.911 & -5.365 \\
\hline & 06 & -1.784 & -1.151 & 10.725 & 6.875 & 0.994 & 0.919 & -7.510 \\
\hline & 07 & -3.130 & -2.006 & -0.432 & -0.282 & 1.020 & 1.002 & -1.729 \\
\hline & 08 & -7.412 & -4.691 & 0.529 & 0.346 & 1.033 & 0.981 & -5.020 \\
\hline & 09 & -2.857 & -1.786 & 2.892 & 1.854 & 1.026 & 0.989 & -3.573 \\
\hline & 10 & -5.190 & -3.243 & -0.108 & -0.068 & 1.006 & 0.974 & -3.178 \\
\hline & 11 & -4.108 & -2.600 & 0.329 & 0.206 & 0.988 & 0.960 & -2.800 \\
\hline & 12 & -7.368 & -4.634 & 2.466 & 1.571 & 1.013 & 0.951 & -6.109 \\
\hline
\end{tabular}




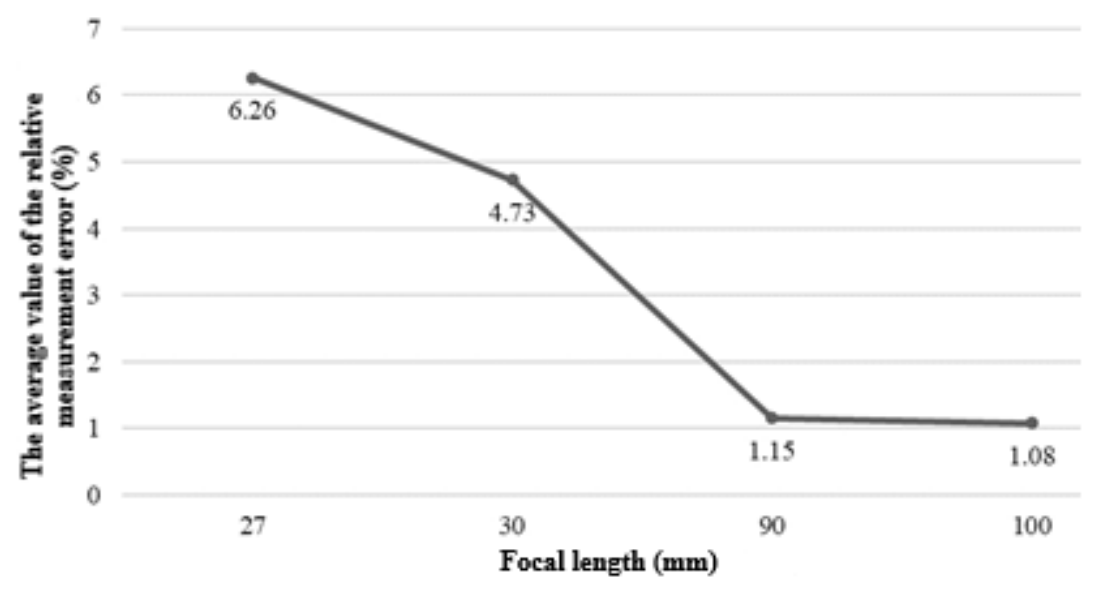

Fig. 3. Dependence of the average value of the relative measurement error for different focal lengths.

The hypothesis of the second study was the presence of significant differences between the conformational features of the original Shetland pony population and the Russian one.

The photographs of horses in two groups were processed using the ImageJ software. Conformation characteristics have been calculated from the images. However, it was not possible to analyze linear measurements for the following reasons: the actual measurements of most horses were unknown, there was no scale ruler or other reference point with reliably known sizes in the frame; the conditions for photographing animals were unknown; significant differences in the graphic resolution of images.

Due to these circumstances, the analyzed parameters are represented by angular parameters and indices of the ratios between vectors drawn through the reference points (Figure 4).

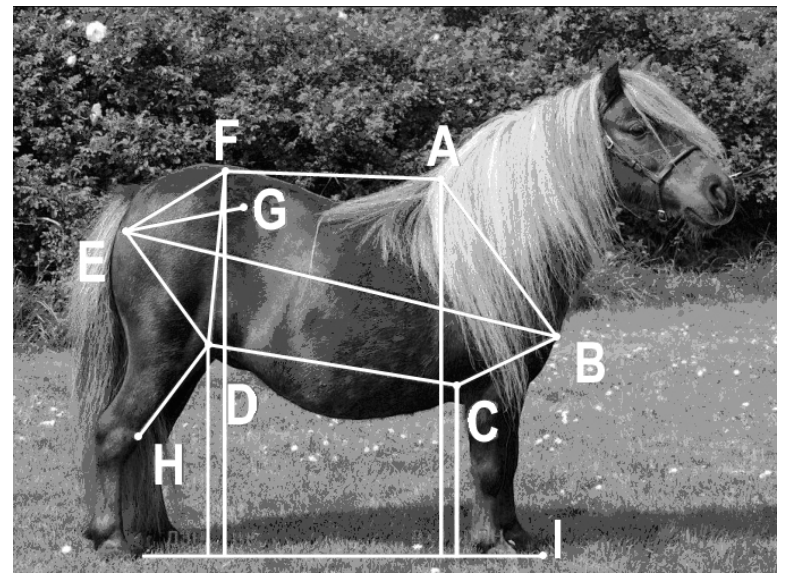

Fig. 4. The reference points location in the photograph of the horse: A - the highest withers point; B humeroscapular joint; $\mathrm{C}$ - the saddle-girth point; D - knee joint; F - the highest crupper point; G hook bone; $\mathrm{H}$ - hock joint; I - "zero" mark.

Since the values of the indicators were close to the normal distribution, this allowed to carry out the analysis of variance and correlation of each population separately.

As can be seen from Table 3, the angular parameters obtained during the processing of photographs and the calculated indices within each population have insignificant fluctuations (the coefficients of variation of individual indicators are rather low). 
Table 3. The processing results of the exterior parameters obtained from photographs.

\begin{tabular}{|c|c|c|c|c|c|c|c|c|c|}
\hline \multirow{3}{*}{\multicolumn{2}{|c|}{ Indicator }} & \multicolumn{8}{|c|}{ Shetland pony populations } \\
\hline & & \multicolumn{4}{|c|}{ Original } & \multicolumn{4}{|c|}{ Russian } \\
\hline & & $\mathrm{M} \pm \mathrm{m}$ & $\min$ & $\max$ & $\mathrm{CV}$ & $\mathrm{M} \pm \mathrm{m}$ & $\min$ & $\max$ & $\mathrm{Cv}$ \\
\hline \multirow{8}{*}{ 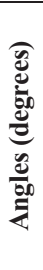 } & AFE & $144.64 \pm 0.37$ & 135.37 & 155.35 & 3.96 & $146.90 \pm 0.41$ & 134.50 & 153.78 & 4.31 \\
\hline & FED & $78.83 \pm 0.23$ & 74.89 & 84.52 & 4.54 & $74.51 \pm 0.52$ & 60.75 & 85.07 & 10.72 \\
\hline & GED & $60.52 \pm 0.20$ & 55.69 & 65.04 & 4.98 & $52.85 \pm 0.43$ & 42.33 & 61.97 & 12.33 \\
\hline & EDC & $142.20 \pm 0.54$ & 128.43 & 154.99 & 5.83 & $144.54 \pm 0.71$ & 130.77 & 164.65 & 7.55 \\
\hline & EDH & $94.81 \pm 0.57$ & 85.93 & 109.84 & 9.16 & $94.38 \pm 0.70$ & 77.38 & 110.89 & 11.31 \\
\hline & DCB & $145.41 \pm 0.36$ & 139.46 & 153.67 & 3.82 & $152.69 \pm 0.78$ & 141.33 & 174.26 & 7.79 \\
\hline & CBA & $78.95 \pm 0.43$ & 66.31 & 89.68 & 8.42 & $76.01 \pm 0.36$ & 66.95 & 82.17 & 7.17 \\
\hline & BAF & $129.49 \pm 0.38$ & 121.71 & 138.07 & 4.46 & $124.21 \pm 0.23$ & 118.17 & 128.69 & 2.85 \\
\hline \multirow{8}{*}{ 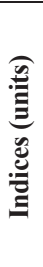 } & TL/BL & $0.91 \pm 0.01$ & 0.78 & 1.11 & 11.91 & $0.91 \pm 0.01$ & 0.77 & 1.01 & 10.20 \\
\hline & IF & 1.22 & 1.14 & 1.28 & 3.90 & 1.12 & 1.04 & 1.25 & 6.39 \\
\hline & OI & 1.03 & 1.00 & 1.05 & 1.69 & 0.99 & 0.95 & 1.01 & 2.50 \\
\hline & HLL/FLL & 1.20 & 1.09 & 1.30 & 6.06 & 1.10 & 0.99 & 1.17 & 6.09 \\
\hline & UI & 0.48 & 0.48 & 0.52 & 5.62 & 0.51 & 0.47 & 0.56 & 5.84 \\
\hline & HLL/WH & 0.57 & 0.55 & 0.61 & 3.39 & 0.56 & 0.52 & 0.61 & 5.86 \\
\hline & FLL/CH & 0.46 & 0.44 & 0.51 & 6.04 & 0.52 & 0.46 & 0.55 & 6.47 \\
\hline & HLL/CH & 0.55 & 0.54 & 0.58 & 2.58 & 0.57 & 0.52 & 0.64 & 6.39 \\
\hline
\end{tabular}

Significant differences between the populations were found in the format indices ( 0.1 units), HLL/FLL (0.1 units), FLL/CH (0.06 units) and angles GED (7.67 $)$, DCB (7.28 $)$, BAF (5.28 $)$.

In the original population, correlation analysis revealed the relationship between 32 traits (Table 4). The strongest correlation was observed for the upstanding index with the FLL/CH indicator $(r=0.9524)$.

Using correlation analysis in the Russian population of Shetland ponies, relationships were identified at a 5\% significance level between 24 indicators (Table 5). As can be seen from the table, completely different relationships were obtained. However, as in the original population, the strongest positive correlation was observed for the upstanding index with the FLL/CH index $(\mathrm{r}=1.0000)$. A fairly strong negative relationship was found between the angular parameters EDC and DCB $(r=-0.8810)$, DCB and BAF $(r=-0.8571)$.

Table 4. Correlation coefficients of physique indices for horses in the original pony population.

\begin{tabular}{|c|c|c|c|}
\hline Indicator 1 & Indicator 2 & Correlation coefficient & p-value \\
\hline $\mathrm{UI}$ & $\mathrm{FLL} / \mathrm{CH}$ & 0.9524 & 0.0003 \\
\hline $\mathrm{EDC}$ & $\mathrm{TL} / \mathrm{BL}$ & 0.9048 & 0.0021 \\
\hline $\mathrm{BAF}$ & $\mathrm{CH} / \mathrm{WH}$ & 0.9048 & 0.0021 \\
\hline $\mathrm{IF}$ & $\mathrm{CH} / \mathrm{WH}$ & 0.8095 & 0.0149 \\
\hline $\mathrm{HLL} / \mathrm{WH}$ & $\mathrm{HLL} / \mathrm{CH}$ & 0.8095 & 0.0149 \\
\hline $\mathrm{AFE}$ & $\mathrm{EDH}$ & 0.7619 & 0.0280 \\
\hline $\mathrm{BAF}$ & $\mathrm{IF}$ & 0.7619 & 0.0280 \\
\hline $\mathrm{AFE}$ & $\mathrm{TL} / \mathrm{BL}$ & -0.7381 & 0.0366 \\
\hline $\mathrm{GED}$ & $\mathrm{CH} / \mathrm{WH}$ & -0.7381 & 0.0366 \\
\hline $\mathrm{AFE}$ & $\mathrm{EDC}$ & -0.7619 & 0.0280 \\
\hline $\mathrm{EDC}$ & $\mathrm{EDH}$ & -0.8095 & 0.0149 \\
\hline $\mathrm{HLL} / \mathrm{FLL}$ & $\mathrm{FLL} / \mathrm{WH}$ & -0.8333 & 0.0102 \\
\hline $\mathrm{HLL} / \mathrm{FLL}$ & $\mathrm{FLL} / \mathrm{CH}$ & -0.8333 & 0.0102 \\
\hline $\mathrm{CBA}$ & $\mathrm{IF}$ & -0.8571 & 0.0065 \\
\hline $\mathrm{FED}$ & $\mathrm{IF}$ & -0.8810 & 0.0039 \\
\hline $\mathrm{EDH}$ & $\mathrm{TL} / \mathrm{BL}$ & -0.9048 & 0.0020 \\
\hline
\end{tabular}

Table 5. Correlation coefficients of physique indices of horses in the Russian pony population.

\begin{tabular}{|c|c|c|c|}
\hline Indicator 1 & Indicator 2 & Correlation coefficient & $\mathrm{p}$-value \\
\hline UI & FLL/CH & 1.0000 & 0.0000 \\
\hline
\end{tabular}




\begin{tabular}{|c|c|c|c|}
\hline FED & GED & 0.9048 & 0.0020 \\
\hline HLL/WH & HLL/CH & 0.8810 & 0.0039 \\
\hline EDC & HLL/CH & 0.7857 & 0.0208 \\
\hline EDC & BAF & 0.7619 & 0.0280 \\
\hline EDC & HLL/FLL & 0.7619 & 0.0280 \\
\hline HLL/FLL & HLL/WH & 0.7143 & 0.0465 \\
\hline DCB & HLL/FLL & -0.7619 & 0.0280 \\
\hline IF & FLL/WH & -0.7857 & 0.0208 \\
\hline IF & FLL/CH & -0.7857 & 0.0208 \\
\hline DCB & BAF & -0.8571 & 0.0065 \\
\hline EDC & DCB & -0.8810 & 0.0039 \\
\hline
\end{tabular}

Batanov S.D. et al. [9] in their work on the model development for a comprehensive assessment of the conformation and productivity of dairy cattle using digital technologies also revealed a positive relationship between the conformational index of physique and measurements characterizing the development degree of the animal's body, which varied from 0,13 to 0,52 .

T. Druml et al. [10] differentiated by the methods of geometric morphometry based on image analysis according to the phenotypic traits of Arabian horses of different genetic origin, having come to the conclusion that this method of phenotyping and analysis can be used to identify the main effects of genetic introgression and predict conformation transitions with an increase and decrease in the genetic contribution of other breeds.

\section{Conclusions}

Analysis of the results obtained allows to conclude that computer processing of photographs obtained by the proposed method allows obtaining fairly reliable data on horse measurements.

Both a camera and a smartphone camera can be used for photography. With this, the camera's FL must be at least $90 \mathrm{~mm}$, and when taking photos with the smartphone camera, an algorithm should be used that corrects the distortion of the optics.

Distortions of photo-measurements can occur as a result of position violation of the markers' layout or the use of a device with FL less than $90 \mathrm{~mm}$ for photography.

The results of this study confirmed the existence of conformational differences between the original and the Russian populations of Shetland ponies. However, carrying out the most qualitative analysis requires a larger number of studied images made under the same conditions in compliance with the requirements of zootechnical photography.

In general, the considered alternative methods and technologies have a number of significant advantages and are suitable for adaptation and implementation to solve these problems in horse breeding. However, in the authors' opinion, it would be useful to synthesize these approaches with the development of a combined solution that makes it possible to assess horse conformation both during image processing and in direct contact with them.

Further development work on high-tech methods for determining and predicting the quality of animals should be devoted to studying the horses' conformation using 3D technologies. In addition, considering that each horse breed is characterized by specific conformational features, the authors believe that the technology of artificial neural networks can be considered as an element of a comprehensive solution for evaluating horse conformation as an alternative method for image classification with subsequent data processing. 


\section{Acknowledgments}

The authors express their heartfelt gratitude and sincere gratitude to the teams of the purebred Arabian, Trakehner, Hanoverian, Akhal-Teke horse breeds of the breeding department of the FSBSI All-Russian Research Institute of Horse Breeding for their help in collecting material for the study.

\section{References}

1. B. Langlois, Analysis of the relationship between conformation and the horse's ability to gallop, trot and jump, 46 (1978)

2. G.V. Kalinkina, Yu.A. Orlova, V.V. Kreshikhina and O.N. Makhmutova, Horse breeding and equestrian sports 3, 9-11 (2016)

3. A.V.Dubrovin, Industry and agriculture 11, 30-7 (2019)

4. G.V. Kalinkina, A.V. Dubrovin and N.V. Abramova, Horse breeding and equestrian sports 1, 4-7 (2020)

5. D. Lewczuk, E. Metera-Zarzycka, PerrJ., 7, 2-14 (2019)

6. T. Druml, M. Dobretsberger, G. Brem, Animal., 9(6), 928-93 (2015)

7. E.M. Pern, V.B. Fileikin, V.A. Podobaev, N.V. Khorolskaya, Static model of a horse under the "HORSE" program. Physiological foundations of increasing the productivity of farm animals: abstracts (Divovo: ARRI of Horse Breeding), 107-8 (1995)

8. L.L. Vikulova, New breeding, physiological, biotechnological methods in horse breeding: collection of scientific papers, 42-53, (1999)

9. S.D. Batanov, I.A. Baranova, O.S. Starostina, Zootechnics 7, 2-8 (2019)

10. T. Druml, M. Horna, G. Grilz-Seger, M. Dobretsberger, G. Brem, Arch. Anim. Breed., 61, 79-85 (2018) 